\section{Re: One-View Chest Radiograph for Initial Management of Most Ambulatory Patients With Rib Pain}

To the Editor: We read with interest the article from Nishimura and colleagues, who proposed that the use of posteroanterior (PA) chest radiograph is sufficient to assess patients with a suspected rib fracture, with no need for a rib series. The article also provides the information that ultrasound has been shown to be a sensitive method for detecting rib fractures. ${ }^{1}$

While praising her work, I would like to add some information in the discussion surrounding the use of lung ultrasound. Lung ultrasound has become an important tool in the extension of the physical examination, and thus, a great ally for clinicians. The use of radiation must follow the ALARA principle, defined as being "as low as reasonably achievable." In this context, there is a preference for modalities that do not require radiation, such as ultrasound. ${ }^{2}$

Another advantage of ultrasound is its cost, being more economically profitable and readily available. An ultrasound allows a faster diagnosis because it can be performed in the physician's office without the need of going to the radiology department. ${ }^{1}$ Besides, the use of contrast and sedation is not necessary. ${ }^{3}$

Many studies have been conducted comparing whether lung ultrasound is superior in accuracy to chest radiography in diagnosing rib fractures following blunt chest wall trauma. These studies have shown that the use of lung ultrasound seems superior compared with a chest radiograph. ${ }^{4}$

However, all studies were small, single-center, and considered at risk of bias on quality assessment, demonstrating the need to reapply more studies in this area since the benefit it would bring to the patient is undeniable.

Lia Zumblick

University of Southern Santa Catarina, Rua Recife, 498,

Tubarão, SC, Brasil liazumblick@gmail.com

Chiaa Esmeralino Mendes Marcon, PhD

University of Southern Santa Catarina, Tubarão, Brasil

To see this article online, please go to: http://jabfm.org/content/ 34/4/878.full.

\section{References}

1. Nishimura E, Finger A, Harris M, Yoon HC. One-view chest radiograph for initial management of most ambulatory patients with rib pain. J Am Board Fam Med 2021;34:144-150.

2. Radzina M, Biederer J. Ultrasonography of the lung. Rofo 2019;191:909-923.

3. Joshi P, Vasishta A, Gupta M. Ultrasound of the pediatric chest. Br J Radiol 2019;92:20190058.

4. Battle C, Hayward S, Eggert S, et al. Comparison of the use of lung ultrasound and chest radiography in the diagnosis of rib fractures: a systematic review. EMJ 2019;36:185-190.

doi: 10.3122/jabfm.2021.04.210195

\section{Response: Re: One-View Chest Radiograph for Initial Management of Most Ambulatory Patients With Rib Pain}

To the Editor: We appreciate the thoughtful comments of Drs. Zumblick and Mendes-Marcon regarding the use of point-of-care ultrasound (POCUS) as an alternative to conventional radiology. We are in complete agreement concerning both the efficacy and advantages of ultrasound for the detection of rib fractures and their complications.

The only current limitation to POCUS is the number of primary care physicians who feel comfortable performing these examinations in their offices. Our medical group rolled out POCUS to all of our free-standing clinics in the fall of 2019. However, because of the limited training available to many of our primary care physicians who already carry heavy patient loads, we have not yet seen a significant decrease in the overall number of chest radiographs or rib series for ambulatory patients with suspected rib fractures.

As more primary care training programs incorporate POCUS into their residency, we hope to see an overall decline in any radiograph imaging for ambulatory patients with possible rib fractures.

Alyssa Finger, BS School of Medicine, Creighton University 5863 Mahimahi Street Honolulu, HI 96821 alyssafinger@creighton.edu

Nishimura Emily, BS Harris Mark, BS Yoon Hyo-Chun, MD, PhD

doi: 10.3122/jabfm.2021.04.210195

To see this article online, please go to: http://jabfm.org/content/ 33/5/878.full. 